ISSN: 0212-5099

E-ISSN: 2695-7809

DOI: 10.24310/BAETICA.2019.v0i39.6776

\title{
A 40 AÑOS DE SU NACIMIENTO. \\ LA REVISTA BAETICA Y EL ESTUDIO \\ DE LA MÁLAGA MODERNA: \\ UN RECORRIDO POR LAS TENDENCIAS \\ HISTORIOGRÁFICAS
}

\author{
Francisco Hidalgo Fernández* \\ Universidad de Málaga
}

\begin{abstract}
RESUMEN
Durante el desarrollo del artículo profundizamos en los artículos que, teniendo como espacio de análisis la provincia de Málaga durante los siglos XVI-XVIII, han sido publicados en la revista Baetica. Nuestro objetivo es, en primer lugar, contextualizar la investigación dentro del debate sobre la historia local para posteriormente realizar un balance de acuerdo con las tendencias historiográficas españolas desde la década de los 70 a la actualidad.
\end{abstract}

PALABRAS CLAVE: Málaga, revista Baetica, historiografía, historia local, historia moderna

Enviado: 16-9-2019

Aceptado: $28-1-2020$

* frhifer@uma.es 


\title{
AT 40 YEARS OF HER BIRTH. THE BAETICA JOURNAL AND THE STUDY OF MALAGA IN THE MODERN AGE. A JOURNEY THROUGH THE HISTORIOGRAPHICAL TRENDS
}

\author{
Francisco Hidalgo Fernández* \\ Universidad de Málaga
}

\begin{abstract}
During the development of the essay we delved into the articles that, having as analysis space the province of Malaga during the 16th-18th centuries, have been published in the Baetica journal. Our goal is, first, to contextualize the research within the debate on local history then take stock in accordance with the Spanish historiographical trends from the 70 s to the present.
\end{abstract}

KEYWORDS: Málaga, Baetica journal, historiography, local history, modern history 
La Universidad española atraviesa en la actualidad una de sus mejores etapas en cuanto a la producción científica se refiere ${ }^{1}$. La amplitud temática, la rigurosidad de los análisis, fruto del excelente aparato teórico construido en los últimos años, y la internacionalización de los resultados hablan por sí mismos. Así, según los datos proporcionados por la Fundación Española para la Ciencia y la Tecnología (FECyT), en el período comprendido entre 2005 y 2014 la excelencia de los trabajos españoles ha ascendido desde el 11,2 \% al 13,4\%, representando, además, algo más del $3 \%$ de la producción global ${ }^{2}$.

La causa de tan positivos resultados hay que buscarla en toda una nómina de revistas, la mayoría de ellas asociadas a centros investigadores o departamentos universitarios que, desde los años 60 al 80, favorecieron la difusión de estudios y la consolidación de investigadores en el marco de un sistema universitario todavía en construcción, posicionándose paulatinamente como auténticos referentes historiográficos. Es en este contexto en el que destacaríamos el nacimiento de publicaciones periódicas como la granadina Chronica Nova en 1968 o, diez años después, la revista Baetica. Estudios de Arte, Geografía e Historia bajo la dirección del geógrafo Eusebio García Manrique $(\dagger 2014)^{3}$. Esta última, y aun con su dilatada trayectoria, no ha tenido todavía el merecido reconocimiento, pese a haber sido escenario idóneo para la publicación de los avances científicos que se producían en una recién creada universidad de Málaga, concretamente desde las disciplinas humanísticas.

El punto de inicio de dicha institución ha de enclavarse en el célebre año 1968, fecha de la l'impossible histoire de Mai, según la definió Pierre

1. Este trabajo forma parte del proyecto de investigación Familias, trayectorias y desigualdades sociales en la España centro-meridional, 1700-1930 [Referencia HAR 2017-84226-C6-2-P] dirigido por Francisco García González y Jesús Manuel González Beltrán y que ha sido posible gracias a la financiación concedida por el Ministerio de Economía y Competitividad del Gobierno de España. Asimismo, el presente artículo ha sido realizado en el marco del contrato predoctoral del I Plan Propio de Investigación y Transferencia concedido por la Universidad de Málaga.

2. Fundación Española para la Ciencia y la Tecnología (2017), "La producción científica excelente se consolidad en España". URL: https://www.fecyt.es/es/noticia/la-produccioncientifica-excelente-se-consolida-en-espana. Además, España se posiciona como el décimo país del mundo en excelencia de su producción científica.

3. El profesor Eusebio García Manrique mantuvo la dirección de la revista desde su nacimiento en 1978 hasta 1996, siendo sucedido por la profesora María Isabel Pérez de Colosía Rodríguez. Una semblanza de su impronta en el mundo académico en M. SÁenz Lorite (1997), 9-13. 
Nora, refiriéndose al movimiento social francés en consonancia directa con el mundo académico ${ }^{4}$. Fue en este año, ya en los estertores de la dictadura franquista, cuando nació la Asociación de Amigos de la Universidad de Málaga persiguiendo precisamente su levantamiento en la provincia y ejemplificando una vez más la íntima relación entre Universidad y sociedad ${ }^{5}$.

La petición fue oída y el 18 de agosto de 1972, bajo el ministerio de José Luis Villar Palasí, se llevaba a efecto mediante el decreto 2566/1972 por el cual quedaban constituidas las universidades de Córdoba, Santander y Málaga:

Artículo segundo- Se crea la Universidad de Málaga, que constará inicialmente de la Facultad de Ciencias Económicas y Empresariales, integrada en la actualidad en la Universidad de Granada, y de la Facultad de Medicina, de nueva creación ${ }^{6}$.

El camino comenzaba y dos años después, en 1974, la Facultad de Filosofía y Letras abría sus puertas dando cabida a la primera promoción que finalizaría los estudios en 1978, fecha en la que, como dijimos más arriba, vio la luz el número primero de la revista Baetica. El referido centro, ubicado desde 1975 en el antiguo Convento de San Agustín del casco histórico malagueño ${ }^{7}$, pasaría diez años más tarde al actual campus de Teatinos, en un edificio adscrito el Movimiento Moderno bajo el amparo de sus arquitectos: Rafael de La Hoz, Gerardo Olivares y José Chastang Barroso $^{8}$.

Como vemos, tan solo hubo de esperar cuatro años, de 1974 a 1978 , para que los profesionales que integraron las áreas del conocimiento de Arte, Geografía e Historia considerasen necesaria la creación de un espacio que diera cabida a la investigación en la ciudad. A partir de entonces y hasta el día de hoy Baetica se posiciona como la revista científica más importante de la provincia de Málaga, albergando en su interior un largo listado de autores que desde su posición más nobel hasta el afianzamiento como

4. P. Nora (1974), 226, recogido por J. M. SÁnchez Preito (2001).

5. F. J. de Vicente Algueró (1976), 13-24.

6. Decreto 2566/1972, de 18 de agosto. BOE, núm. 235, de 30 de septiembre de 1972, p. 17515.

7. Desde momentos anteriores a la creación de la facultad un edificio de la Alameda Principal, emplazamiento actual del Archivo Municipal, albergó la Sección de Letras del Colegio Universitario en Málaga, dependiente de la universidad de Granada.

8. A. J. Santana Guzmán (2012), 272. 
personalidades en sus áreas de conocimiento han contribuido a mantener el rigor y la periodicidad de dicha publicación.

No obstante, queda aún recorrido por andar. Posicionar la revista en estándares de calidad más elevados es uno de los propósitos de su actual dirección, encabezada por la profesora Pilar Pezzi Cristóbal. Es por ello por lo que, tras 37 números, la lógica tendencia a la especialización hizo que esta pasara a integrar en exclusividad trabajos de Historia Moderna y Contemporánea quedando adscrita al departamento homónimo y produciéndose, además, su entrada en el Open Journal System junto con otras diecinueve revistas de la misma entidad malagueña. En definitiva, un cambio que lejos de romper con sus profundas raíces, pretende hacer uso de ellas para ubicar Baetica, la investigación modernista y contemporaneísta $\mathrm{y}$, por consiguiente, a la universidad de Málaga como un referente de la producción histórica.

A lo largo de este artículo, pretendemos hacer un recorrido por los distintos estudios que sobre la Málaga moderna se han ido publicando desde su creación, poniéndolos en relación con las distintas líneas historiográficas desarrolladas en España desde los años 70 partiendo del debate generado en torno a la producción histórica de lo local. Asimismo, y aun siendo conscientes que no manejamos la totalidad de la producción existente para la provincia, nos apoyaremos en este primer acercamiento para vislumbrar las carencias que todavía arrastra la historia de Málaga y cuáles han de ser algunas de las líneas sobre las que actuales y futuros investigadores han de profundizar, con el objetivo de mejorar el conocimiento de un espacio geográfico trascendental para la Monarquía Hispánica entre los siglos XVI y XVIII.

\section{MÁlAGA Y EL DEBATE EN TORNO A LA HISTORIA LOCAL}

Puesto que nuestro interés radica en los artículos dedicados al estudio de la provincia de Málaga en el período moderno, consideramos especialmente interesante relacionarlo con el debate generado entre finales de los 90 y principios de los 2000 en torno a la importancia o no de una historia local muy cultivada desde el último tercio del siglo XX. Entendida por unos como una actividad de corte erudito decimonónico, estos consideraron que debió estar distanciada del modelo universitario9; para otros, por el contrario, no es más que una fracción territorial del análisis, una delimitación que ha

9. J. Pro Ruiz (1995) recogido por R. García Cárcel (2001), 191. 
de ser posteriormente comparada con escalas de tipo regional, nacional e, incluso, global o total ${ }^{10}$. Sin embargo, prioritariamente se debe de explicar el porqué de esta proliferación, pues como todo suceso responde a una serie de variables históricas que hicieron posible su crecimiento.

La mayoría de los autores que han escrito sobre el tema vinculan la eclosión de la investigación de ámbito local con el proceso político de la transición española, etapa de construcción de un estado autonómico que motivó la elaboración de unas historias regionales, en muchos casos politizadas por el nacionalismo periférico, y la consiguiente reacción de historias de España imbuidas también de tintes nacionalistas. En definitiva, unos discursos que poco o nada beneficiaron al conocimiento riguroso del pasado ${ }^{11}$. Frente a estas, desde finales de los 80 e inicios de los 90 se sucedieron toda una serie de obras convertidas hoy en auténticos referentes historiográficos. Nos referimos al denominado "legado del 92" donde se enclavan entre otras las Historias de España dirigidas por Domínguez Ortiz, Artola o Jover Zamora ${ }^{12}$.

No obstante, como hemos adelantado, la producción local que podríamos llamar "finalista" ha de ser diferenciada de otra "expansiva" en su vertiente comparada. A fin de cuentas nos referimos a lo que el profesor A. M. Bernal dividió entre la Historia local y la investigación histórica local, siendo la última "un mero factor coadyuvante al servicio de una investigación más general"13.

Pero hay algo más. La creación de centros universitarios en las distintas provincias durante el tardofranquismo y la transición ayudó, sin duda, al desarrollo de una investigación de tipo local o regional gracias a una documentación municipal conservada que no había sido aún partícipe de estudios aplicando métodos científicos propios. En el caso de la Málaga dieciochesca destacaríamos, por ejemplo, la obra de Villas Tinoco, sin olvidarnos de la totalidad de la primera generación de profesores que engrosaron el Departamento de Historia Moderna.

En conclusión, el número de centros periféricos creció más allá de la Universidad Central de Madrid -Complutense desde 1970-, el volumen de profesores aumentó considerablemente integrando estos los departamentos de nueva creación y, por consiguiente, explotando líneas históricas aún

10. J. A. Lacomba Abellán (2008).

11. R. García Cárcel (2001), 189-192.

12. D. García Hernán, C. Soriano Triguero, F. Negredo del Cerro y A. Sanz de Bremond y Mayans (1994).

13. A. M. Bernal (2003), 224. 
vírgenes ${ }^{14}$. Sin embargo, falta un elemento esencial: la influencia de la historiografía europea.

Podríamos decir que la escuela francesa es la que mayor influjo tuvo en la española ${ }^{15}$, siendo sucedida en parte por la anglosajona en los últimos años, especialmente en lo concerniente a la historia eminentemente política de tinte no marxista seguidora de la producción de Elliot ${ }^{16}$. En el caso de la introspección sobre lo social hemos de nombrar la segunda y tercera generación de Annales, así como, en menor medida, la microhistoria italiana, asumiendo esta última unos tintes más locales fruto de su escala analítica ${ }^{17}$. No obstante, como afirma García Cárcel la microhistoria "ha estado raquitizada" en España, preguntándose incluso si la historia local la ha "asfixiado", debido a la inexistencia de una tradición metodológica que poco o nada se asemeja a la italiana ${ }^{18}$. Esta situación obedece, según asevera Rey Castelao, a unos lazos falsos entre la historia local y la microhistoria, disciplinas ambas que no comparten ni objeto de estudio, ni amplitud temporal, ni tampoco métodos de acercamiento similares:

Las diferencias con la microhistoria radican en que para la local history lo esencial es la interacción entre las continuidades a largo plazo, creadas por limitaciones territoriales, y los ritmos a medio plazo generados por las respuestas locales a nuevos estímulos; el elemento clave es la comunidad y no el individuo; el tiempo, el más largo posible, sin rupturas por época; y el método, el estudio de la organización y estructura sociales y de su escala de valores -aunque practica también el estudio de historia familiares o árboles genealógicos de familias comunes- $-^{19}$.

Sin embargo, continuando con las palabras de la misma autora, el "prestigio editorial" ${ }^{20}$ de la microhistoria ha sido utilizado en nuestro país para disfrazar una investigación de lo local señalada por sus detractores, debido al deterioro de su consideración dentro del mundo académico.

14. Todo este proceso que brevemente esbozamos se produjo en otros países tras 1945. La Francia posbélica se caracterizó por vivir momentos de novedad investigadora apoyado en un aumento de docentes desde los 3.000 a los 8.000 entre 1950 y 1967. M. Marín Gelabert (2001), 109-111.

15. F. García González (2009).

16. R. García Cárcel (2001), 193.

17. E. Hernández Sandoica (2004), 479-506.

18. Ibidem, 192; J. A. Lacomba Abellán (1995).

19. O. Rey Castelao (2009), 118.

20. Ibidem. 
Tras este debate, todo parece indicar que la inclinación favoreció a los contrarios de lo local -incluida la buena historia local-, pues pese a mantenerse en la actualidad, su peso ha disminuido. El asunto que nos concierne en el presente texto es, sin embargo, delimitar en qué situación se encuentra el conocimiento de la Málaga moderna, siendo conscientes de que los municipios que conforman dicha provincia reúnen los requisitos idóneos como para construir, tal y como se ha venido haciendo, una historia micro en su nivel territorial, pero con un alto nivel relacional con las investigaciones de lo macro.

La totalidad de los artículos publicados en Baetica desde 1978 a 2018 referentes a la Edad Moderna elevan su número hasta los 287, incluyendo aquí no solo los provenientes de las áreas puramente históricas, sino también de disciplinas como la Historia del Arte y las Ciencias y Técnicas. Asimismo, y con el fin de enmarcar la cronología de los trabajos, se excluyen de este dato aquellos que, aún realizados por modernistas, se enfocan en la centuria decimonónica. De todos ellos, como se observa en la Tabla 1, el $75,3 \%$ encuadran su investigación en la provincia malagueña, siendo la capital la más estudiada, seguida de sus principales municipios: Antequera, Vélez-Málaga y, en menor medida, Ronda y Marbella, integrada esta última en el grupo "Otros".

Tabla 1. Artículos de Baetica según zona de estudio. Período 1978-2018

\begin{tabular}{|c|c|c|}
\hline Zona de ESTUdio & VALOR ABSOLUTO & PorCENTAJE \\
\hline Málaga & 160 & $74 \%$ \\
\hline Antequera & 24 & $11,1 \%$ \\
\hline Vélez-Málaga & 13 & $6 \%$ \\
\hline Ronda & 3 & $1,4 \%$ \\
\hline Otros & 7 & $3,3 \%$ \\
\hline Provinciales & 9 & $4,2 \%$ \\
\hline Total & $\mathbf{2 1 6}$ & $\mathbf{1 0 0} \%$ \\
\hline
\end{tabular}

\begin{tabular}{|c|c|c|}
\hline Artículos Málaga provincia & 216 & $75,3 \%$ \\
\hline Resto artículos & 71 & $24,7 \%$ \\
\hline Total & $\mathbf{2 8 7}$ & $\mathbf{1 0 0} \%$ \\
\hline
\end{tabular}

Fuente: elaboración propia 
Como decimos la capital malagueña aglutina la mayoría de los trabajos. Esta situación no ha de explicarse exclusivamente por la cercanía de la documentación, sino también por la relevancia del enclave en el devenir de la España moderna y, por tanto, en la proclive vinculación con amplios fenómenos históricos, característica de la producción local como anteriormente apuntamos.

Su ubicación en los márgenes meridionales de la Península la convirtió en un punto referencial del Mediterráneo. Por ello, desde el momento de la conquista, y aún dependiente administrativamente del reino granadino incorporado ya a la corona de Castilla, estuvo inserta en el conjunto de los procesos sociopolíticos que durante estas centurias se produjeron llevándola a una época áurea en las postrimerías de la modernidad.

Aunque posteriormente incidiremos en las distintas tendencias historiográficas desarrolladas en el mundo académico desde las décadas de los 70-80, consideramos de interés hacer algunos apuntes previos sobre las líneas más generales -historia política, social, económica, cultural y del arte- atendiendo a los datos insertos en la Tabla 2.

Tabla 2. Líneas de investigación en la provincia de Málaga

\begin{tabular}{|c|c|c|c|c|c|}
\hline Localidad & H. $^{\text {a }}$ Política & H. $^{\text {a }}$ Social & H. $^{\mathbf{a}}$ Económica & H. $^{\mathbf{a}}$ Cultural & H. $^{\text {a }}$ del Arte \\
\hline Málaga & 37 & 61 & 31 & 20 & 11 \\
\hline Antequera & 3 & 10 & 3 & 6 & 2 \\
\hline Vélez-Málaga & 4 & 3 & 6 & 0 & 0 \\
\hline Ronda & 1 & 1 & 0 & 1 & 0 \\
\hline Otros & 0 & 5 & 1 & 0 & 1 \\
\hline Provincia & 0 & 4 & 3 & 2 & 0 \\
\hline Total & 44 & 85 & 44 & 29 & 14 \\
\hline
\end{tabular}

Fuente: elaboración propia

Palpable es la predominancia de los estudios socioeconómicos en todas las localidades incluidas en el cuadro. Centrándonos en Málaga, los estudios sociales representan algo menos del $40 \%$, seguido de la investigación en materias políticas, incluyéndose aquí tanto la local como estatal y los asuntos bélicos, y la historia económica. En el lado opuesto, la investigación de los aspectos artísticos malagueños queda relegada al $6.9 \%$, en consonancia con lo visible en el resto de los municipios referenciados. Este hecho, que contrasta con la riqueza ornamental de la provincia, se explica por el nacimiento de otra revista en 1980 dependiente del Departamento de Historia del Arte de 
la universidad de Málaga: Boletín de Arte ${ }^{21}$. De hecho, esta fecha marca un hito total en el declive de estudios sobre la cuestión como puede observarse en el Gráfico 1, desapareciendo su presencia desde el intervalo 2001-2005.

\section{Gráfico 1. Evolución de las temáticas. Período 1978-2018}

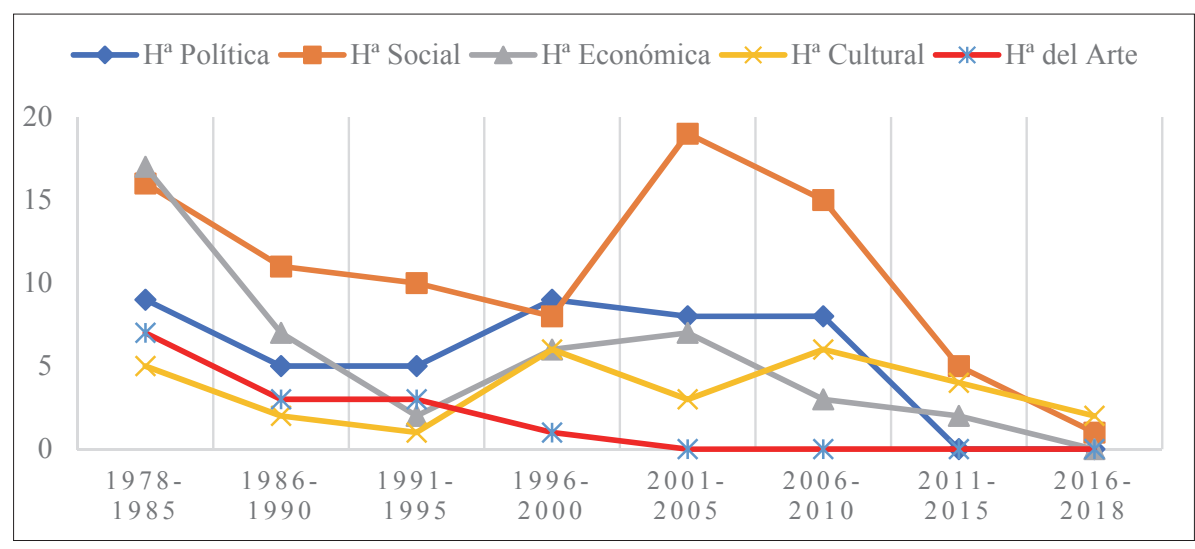

Fuente: elaboración propia

\section{BAETICA Y LAS TENDENCIAS HISTORIOGRÁFICAS ESPAÑOLAS}

Desentrañemos ahora cada uno de los datos proporcionados por la gráfica anterior. Como apuntamos para el caso de la historia local, la transición española supuso un momento de cambio en el terreno académico. La nueva organización territorial, la apertura, sobre todo en el posterior decenio, y especialmente los intereses investigadores de una nueva generación de historiadores recién incluidos en el organigrama universitario van a favorecer el cambio. Empero no podemos reducir el comienzo de todo a una sola fecha. Como apunta García Cárcel, "si nos atenemos a la historiografía positivista tradicional, y respecto al franquismo, la ruptura se produciría en los años sesenta", mientras que, para la historia económica,

21. La revista Boletín de Arte se ha consolidado en los últimos años obteniendo el sello FECyT, integrándose en el tercer cuartil del Scimago Journal \& Country Rank e incluyéndose en la categoría B de la Clasificación Integrada de Revistas Cientificas. 
hubo que esperar hasta la segunda mitad de los $80^{22}$.

Pero no solo España sufrió este proceso. A finales de los 70 los grandes paradigmas historiográficos surgidos tras la Segunda Guerra Mundial entraron en crisis dando paso a una "proliferación, y hasta superabundancia, de escritos de reflexión, de fundamentación, de método y de teoría y hasta de admonición y arenga" ${ }^{23}$, tal y como afirmaba Aróstegui a mediados de los 90, hecho que Rey Castelao ejemplifica en el cambio de subtítulo de la revista Annales que pasaba en 1989 del célebre Economies, Sociétés, Civilisations a Histoire, Sciences Sociales ${ }^{24}$, lo que acabó siendo un "giro... [de] éxito parcial". Pero la célebre revista francesa no fue la única en esta "desorientación", la anglosajona Past and Present o la italiana Quaderni Storici modificaban también el grado de atención a sus clásicos temas ${ }^{25}$.

\subsection{Los estudios socioeconómicos. Una tendencia en auge}

Como se anticipó, los estudios socioeconómicos han asumido en la revista Baetica la mayor parte de las páginas concernientes a la Edad Moderna. La amplitud del concepto se une a la débil divisoria existente entre aquello que podemos denominar historia social, cultural o política. ¿Dónde incluimos, por ejemplo, los análisis sobre los regidores de cabildo, las rebeliones o el problema morisco? Son cuestiones eminentemente políticas con una gran repercusión en lo social. Podríamos decir, por ende, que la división en materias responde no tanto al tema tratado sino más bien al objetivo del estudio ${ }^{26}$.

Es cierto que la historia social en España no cambia de forma drástica con el fin de la dictadura, anteriormente autores como Domínguez Ortiz ya publicaron obras de gran interés historiográfico como La sociedad española en el siglo XVIII (1955) o, años más tarde, Las clases privilegiadas en la España del Antiguo Régimen (1973), entre otras. No obstante, es cierto que a mediados de los 70 comienza a vislumbrarse un giro en el tratamiento de temáticas con gran tradición como la Inquisición, imbuida ahora por "la voluntad de superar la polarización tradicional de los juicios de valor" ${ }^{27}$.

22. R. García CÁrcel (2001), 186-187.

23. J. Aróstegui Sánchez (1995), 129.

24. O. Rey Castelao (2009), 99.

25. Ibidem, 99-101.

26. B. Clavero (1991).

27. R. García Cárcel (2001), 188.

(C) Baetica. Estudios Historia Moderna y Contemporánea, 39, 2019, 13-44. Facultad de Filosofia y Letras, Universidad de Málaga. Departamento de Historia Moderna y Contemporánea 
Baetica asumió durante sus primeros números las investigaciones a este respecto de la mano de Joaquín Gil Sanjuán y María Isabel Pérez de Colosía Rodríguez, seguidores de la línea renovadora de aquellos momentos, y que tuvo su etapa más brillante entre 1976 y 1986 con la celebración de numerosos congresos nacionales e internacionales o la publicación de una amplia bibliografía entre la que habría que destacar la traducción en 1983 de A History of the Inquisition of Spain (1906-1907) de Henry Charles Lea ${ }^{28}$. De hecho, el propio Gil Sanjuán en el artículo publicado en 1978, decía:

Metodológicamente, hasta una época no muy lejana, este tema se ha tratado por la historiografía bajo un punto de vista polémico, pues no era fácil zafarse de las corrientes de ataque y defensa que se daban sobre esta institución. Hoy en día, gracias a los esfuerzos de ciertos historiadores, las corrientes investigadoras discurren por otros cauces ${ }^{29}$.

Fueron precisamente algunos de los historiadores de este "esfuerzo" señalado por Gil Sanjuán, el inglés Kamen, cuya obra sobre la institución había sido traducida al español en 1967, o García Cárcel, autor dos años antes de los Orígenes de la Inquisición Española. El tribunal de Valencia. Por otro lado, Pérez de Colosía mantuvo una misma orientación utilizando asiduamente en sus aparatos críticos una producción actual, haciendo con ello a Baetica portavoz de las nuevas tendencias historiográficas de la época, tal y como manifestó Molas Ribalta sobre la que fue su directora:

En suma en su obra [la de María Isabel Pérez de Colosía] se reflejan las tendencias y las influencias de toda una generación y todos nos felicitamos y la felicitamos por los resultados que ha conseguido y que nos ofrece como fruto de toda una vida de investigación ${ }^{30}$.

Empero, el interés por el Santo Oficio pronto derivó hacia el estudio de las minorías, principalmente morisca. La cercanía de la universidad de Granada y, en ella, de la escuela de Manuel Barrios tuvo un lógico influjo. Los primeros trabajos que sobre estos se publicaron, de nuevo, de la mano de Gil Sanjuán y Pérez de Colosía, casaron fundamentalmente con los análisis de recientes obras como Historia de los moriscos de Domín-

28. R. García Cárcel (1996), 231.

29. J. Gil SAnJuÁn (1978), 313.

30. P. Molas Ribalta (2006), 10. 
guez Ortiz y Vincent, cuya relevancia, como afirma Soria Mesa y Otero Mondéjar, viene dada por su absoluta y actual vigencia ${ }^{31}$, o la realizada por Garzón Pareja sobre la actividad sedera, precursora en la relación con el sistema de producción ${ }^{32}$. Mientras otros estudios eran por aquel entonces reeditados, como el pionero trabajo etnológico y antropológico de Caro Baroja: Los moriscos del reino de Granada (1976), cuya primera edición databa de 1957.

Con ello, estas primeras investigaciones tuvieron un profundo calado en la universidad malagueña y años más tarde, en 1988, Juan Jesús Bravo Caro publicaba en el número 11 de Baetica un artículo sobre el fenómeno repoblador en Algarrobo (Málaga) donde se percibía la influencia de la escuela granadina ${ }^{33}$, así como la producción de la que fuera su maestra: la Dra. Colosía. Ya en 1992, y bajo su dirección, defendió la tesis doctoral sobre la política repobladora de Felipe II en la Taha de Comares ${ }^{34}$.

Por su parte, la minoría judeoconversa también tuvo el interés de los historiadores malagueños, seguidores, una vez más, de la "revolución conceptual" de Domínguez Ortiz y Caro Baroja ${ }^{35}$. Pérez de Colosía publicaría en 1985 el primer estudio sobre la viña del jurado Alonso Gamarra como centro del criptojudaismo malagueños del XVII, tema sobre el que posteriormente profundizó la profesora Roldán $\mathrm{Paz}^{36}$. Una investigación, la de la Dra. Roldán, que sin duda alguna logró paliar el vacío en cuanto a la investigación de los judeoconversos, así como equiparar la balanza entre los estudios que de estos y los moriscos se han desarrollado en la Andalucía oriental, gracias a su tesis doctoral defendida en $2015^{37}$.

Manteniéndonos en el siglo XVII pero virando hacia el interior geográfico, encontramos la investigación desarrollada para la ciudad de Antequera. Lo cierto es que, pese a que el interés por referida urbe vino dado, en primer lugar, por los historiadores del arte y los medievalistas, a inicios de los 2000 comenzaron a publicarse en Baetica algunos artículos sobre la localidad. Reseñables son, en este sentido, las introspecciones que sobre los bienes municipales hizo Fernández Paradas ${ }^{38}$ o los estudios acerca de

31. E. Soria Mesa y S. Otero Mondéjar (2010), 1-2.

32. R. García Cárcel (1977), 91.

33. J. J. Bravo Caro (1988).

34. J. J. Bravo Caro (1995).

35. M. R. Cañas Pelayo (2015), 221-224.

36. M. ${ }^{a}$ I. Pérez de Colosía Rodríguez (1985); L. Roldán Paz (2010).

37. L. RoldÁn PaZ (2015).

38. M. Fernández Paradas (2000); (2001). 
los extranjeros y procesados inquisitoriales realizados por Bravo Caro y Roldán Paz respectivamente ${ }^{39}$.

Pero al hablar de la Antequera de los siglos XVI y XVII hemos de remitirnos a los estudios de León Vegas que, aún relacionándose más con los aspectos devocionales resultan esenciales para la comprensión de la sociedad de tan ilustre ciudad en la Edad Moderna ${ }^{40}$, entre los que podríamos citar el artículo sobre un tema escuetamente tratado en la historiografía española como es el referente a la sexualidad ${ }^{41}$. No obstante, profundizaremos en la producción de la profesora León en siguientes epígrafes.

Es en la investigación sobre el siglo XVIII donde los estudios económi$\cos$ se han dejado ver con mayor frecuencia ${ }^{42}$. Por un lado, la trayectoria de Villas Tinoco evolucionó entre su interés por el órgano de poder municipal y por el modelo de la organización artesanal de la ciudad de Málaga, base fundamental para aquellos que en la actualidad pretenden aproximarse al entramado gremial de la época. Incluyendo en el número primero de Baetica un estudio aproximativo para el análisis de las corporaciones artesanales, su investigación doctoral finalizó con una imprescindible obra sobre los gremios malagueños en el reinado de Felipe $\mathrm{V}^{43}$, que se unía a otra de referencia publicada anteriormente sobre la urbe de Barcelona, la de su director: Pere Molas Ribalta ${ }^{44}$.

La investigación del profesor Villas se sitúa en un momento de transición de dos formas de entender el mundo artesanal. Por un lado, se mantenía una tendencia tradicional altamente influencia por los juicios de valor de los textos ilustrados españoles y, especialmente, de la obra de Adam Smith. La visión de las agrupaciones como freno para el avance económico de la monarquía era generalizada pese a que a inicios del siglo XX ya algunas obras apuntaban hacia otra dirección. Avanzando en la centuria, el freno que supuso la dictadura franquista fue superado con la publicación de trabajos altamente fundamentados, alejados de los análisis apologéticos

39. J. J. Bravo Caro (2003); (2004); L. Roldán Paz (2004).

40. Para un balance historiográfico sobre la Antequera moderna vide M. LEÓN VEGAS (2011).

41. M. León Vegas (2004). Habría que citar también el trabajo de M. T. López Beltrán (2008).

42. No obstante, destacamos los artículos de M. T. López Beltrán (1979); (1997); (1999) gran conocedora del puerto de Málaga y las relaciones comerciales en el tránsito a la modernidad.

43. S. Villas Tinoco (1978); la tesis doctoral defendida en 1980 fue posteriormente publicada, vide S. Villas Tinoco (1985).

44. P. Molas Ribalta (1970). 
realizados por los historiadores del régimen, como, por ejemplo, la Historia de la previsión social en España de Rumeu de Armas (1944) altamente influyente en una generación de historiadores entre los que se encontraron Molas Ribalta y Villas Tinoco, pero también otros como Bernal, Collantes o García Baquero.

Por otro lado, a partir los años 90, más en el resto de Europa que en España, el interés por el sector artesanal ha crecido exponencialmente alejándose de la visión jurídica y organizativa precedente, volcándose en las problemáticas eminentemente sociales ${ }^{45}$. Esta última cuestión ha de ser campo de exploración en el futuro. Partiendo de los análisis del Dr. Villas, la situación historiográfica actual permitiría profundizar en las trayectorias individuales, las relaciones laborales en su dimensión social o en el levantamiento de redes de relaciones desbordando el ámbito artesanal y local.

Pero su investigación no se circunscribe únicamente al gremio. El cabildo, como órgano rector de la ciudad, fue también una vía de exploración. Nos retrotraeríamos a la que fue su tesina sobre Málaga a fines de la Edad Moderna ${ }^{46}$, en la que aplicando los marcos metodológicos de la historia local amplió el estudio a múltiples facetas: política, económica, social y cultural; vinculándolo a su vez con un proceso de primer orden: la revolución francesa. Fue esta línea, sobre la que avanzaremos más adelante, la seguida posteriormente por Pilar Pezzi Cristóbal, centrada esta vez en la localidad de Vélez-Málaga.

Ubicada temporalmente a inicios del siglo XVIII, la Dra. Pezzi Cristóbal se introdujo en el análisis de los aspectos económicos del cabildo veleño en sus primeras investigaciones ${ }^{47}$, aunque como anteriormente el profesor Villas, la tesis que finalizó en el año 2000 no se circunscribió únicamente a ellos ${ }^{48}$.

Sin duda alguna, el camino iniciado en cuanto al estudio del aparato administrativo desde el punto de vista hacendístico ha de ser seguido tanto para Málaga como para el resto de las localidades: Antequera, Ronda o Marbella. No obstante, como se pudo observar en la Gráfica 1, el interés

45. No queremos decir con ello que fueran inexistentes anteriormente. Las luchas internas y externas de los gremios fueron un tema tratada durante los 70 , vide J. JACQUES (1972). Un estado de la cuestión actuales se encuentra en R. Hernández García y J. D. GonzÁlez Arce (2015).

46. S. Villas Tinoco (1979).

47. P. Pezzi Cristóbal (1994); P. Pezzi Cristóbal (1995).

48. Algunos aspectos de su tesis doctoral han sido publicados en P. Pezzi Cristóbal (2003a) y P. Pezzi Cristóbal (2003b). 
por la historia económica ha disminuido desde inicios del presente siglo, hecho observable en el conjunto de la geografía española, en parte por la conformación de departamentos de historia económica más nutridos por economistas que por historiadores ${ }^{49}$.

La vertiente social ha estado también presente en la trayectoria de la actual directora de Baetica ${ }^{50}$. Centrándose en unas oligarquías locales profusamente estudiadas en los últimos veinte años, la investigación sobre la élite veleña atenuó la escasez de trabajos sobre la cuestión que caracterizó la Andalucía oriental ${ }^{51}$. No obstante, las ausencias siguen siendo considerables en el resto de la provincia donde son altamente necesarias indagaciones aplicando, no ya los métodos prosopográficos sino el levantamiento de redes de relaciones ${ }^{52}$.

Ciertamente, la ciudad de Málaga no ha tenido estudios profundos de su oligarquía municipal durante el siglo XVIII desde el terreno prosopográfico $^{53}$, aunque cabe señalar los trabajos de Ivanova Ocaña ${ }^{54}$, no incluidos en la revista, o los de Begoña Villar, básicos para la extracción de elementos comunes sobre la población extranjera, particularmente perteneciente a la élite comercial establecida en esta ciudad portuaria.

Los extranjeros, como ella mismo escribió, suscitaron desde los años 60 el interés de historiadores entre los que habría que citar nuevamente a Domínguez Ortiz. En este sentido, dos son las direcciones, señaladas por la profesora Villar, que tomó la investigación en sus primeras fases: el interés de historiadores franceses por conocer el grado de movilidad y las actividades desarrolladas por sus paisanos; $y$, desde el territorio insular canario, interesado mayormente en vislumbrar las relaciones entre dicho archipiélago con otros países de la Europa occidenta $1^{55}$. Posteriormente, este primer avance se expandió hacia un aumento exponencial de la investigación sobre los extranjeros en la que se enclavó su tesis doctoral ${ }^{56}$.

49. R. García CÁrcel (2001), 199-200.

50. P. Pezzi Cristóbal (2006).

51. E. Soria Mesa (2000), 188-189.

52. Un estudio sobre la oligarquía antequerana lo encontramos en F. Hidalgo Fernández (2018).

53. En S. Villas Tinoco (1996) se realiza un estado de la cuestión sobre los estudios realizado para el cabildo de Málaga durante la Edad Moderna.

54. I. Ocaña Cuadros (2002); (2009).

55. M. B. Villar García (2003), 15-16.

56. M. B. Villar García (1989). 
Empero, aunque su recorrido académico mantuvo una preocupación continuada por este sector, nos parece destacable un artículo publicado en el número 6 (1983) en el que proponía una metodología de acercamiento a la vivienda en el siglo XVIII ${ }^{57}$. Este apuntado interés se origina por la novedad del estudio de la vida cotidiana y la cultura material a inicios de los 80, línea de gran proyección actual ${ }^{58}$. Las influencias de la autora claramente hay que buscarlas en la escuela francesa: Civilización material y capitalismo de Braudel; La vie quotidienne de Poussou; o La maison reuennaise de Bardet. Pese a ello, la profesora Villar no continuó esta senda, quedando yermo dicho campo de exploración para futuros investigadores de lo cotidiano.

Otra línea especialmente relevante va a ser la acometida por el profesor Sanz Sampelayo dentro de la célebre Demografía Histórica. Aunque entre su amplia producción lo cierto es que no son muy numerosos los artículos que sobre la Málaga moderna (anterior a 1800) se incluyen en los índices de Baetica. Sin embargo, la excelencia del historiador y de esta variante de lo social hacen obligada su mención.

La Demografía Histórica tuvo durante los años 70-80 su etapa de mayor esplendor ${ }^{59}$. Aunque las raíces en España se hundían en los 60, fue en la siguiente década cuando se fueron publicando estudios bien procedentes de jóvenes investigadores formados en la escuela de Annales, o bien por hispanistas franceses como Vilar o Benassar ${ }^{60}$. Esta tendencia en alza desembocó en la constitución de la Asociación de Demografía Histórica (ADEH) en 1983 con una predominancia de la historia rural, en claro declive desde los $90^{61}$.

De los artículos de Sanz Sampelayo, con una excelente tesis doctoral sobre la Granada del siglo XVIII ${ }^{62}$, destacamos la tipología poblacional de Málaga y su provincia a partir del censo de Floridablanca, fundamental para cualquier introspección sobre la estructura social de los municipios malague$\tilde{n} \mathrm{~s}^{63}$. Aun así, la demografía, pese a mantener su fortaleza como disciplina independiente ha evolucionado hacia posiciones más cualitativas, pudiendo citar aquí, por ejemplo, la historia social a través del estudio de la familia.

57 . M. B. Villar García (1983).

58. M. A. Pérez Samper (2009); I. Arias de Saavedra Alías (2012); G. Franco Rubio (2012); M. García Fernández (2013); o M. Birriel Salcedo (2017), son algunos de los investigadores con mayor prestigio actualmente en este terreno historiográfico.

59. I. DUBERT (2015).

60. J. M. Pérez García (1990), 42.

61. F. García GonzÁlez (2007), 107-108.

62. J. F. Sanz Sampelayo (1980).

63. J. F. Sanz Sampelayo (1988). 
Desarrollada esta última de forma coetánea a la $\mathrm{ADEH}$, gracias a las aportaciones de Eiras Roel y Chacón Jiménez, es considerada actualmente como una de las vías más fructíferas en cuanto a la exploración de la sociedad, con múltiples estados de la cuestión a los que ni el espacio ni la temática del presente texto nos permiten acercarnos ${ }^{64}$.

Por último, la beneficencia ha sido otro los puntos de referencia de la investigación malagueña. Las distintas actividades asistenciales de la provincia han sido estudiadas por Pérez de Colosía o León Vegas, mientras que Pezzi Cristóbal indagó en la variante educacional ${ }^{65}$. Pero fue Reder Gadow la que prestó mayor atención a estas instituciones, orientada fundamentalmente en la infancia con estudios sobre el colegio de niñas huérfanas o los niños de la providencia ${ }^{66}$, y es que el estudio de los ciclos vitales, enfocado actualmente en la juventud, se focalizó durante los años 80 y 90 en la edad pueril, fundamentalmente, en marginados, como los expósitos, y las instituciones que les dieron cobijo ${ }^{67}$.

Como decimos, esta línea iniciada en Málaga por la profesora Reder es hoy una de las más halagüeñas en cuanto a la consecución de conclusiones en lo social, por lo que son todavía muchas las variantes, incluso desde la infancia ${ }^{68}$, por explorar: desde la juventud, la incorporación al mundo laboral, la formalización del matrimonio con la consecuente liberación de la patria potestad o el carácter desequilibrador de referida edad ante la desobediencia; para la vejez, la solidaridad intergeneracional o la contraposición con características estereotipadas, son tan solo algunas de las temáticas abordadas por la historiografía actual ${ }^{69}$.

\subsection{Entre la historia política y la representación del poder}

Bajo la lógica de lo local los estudios a los que haremos referencia en este epígrafe se circunscriben casi en su totalidad al órgano de gobierno

64. Nos remitimos a una obra de compendio sobre los distintos estados de la cuestión desde inicios de los 90, vide F. Chacón JimÉnez (2014).

65. M. León Vegas (2002); M. I. Pérez de Colosía Rodríguez (2003); P. Pezzi Cristóbal $(2003 c)$.

66. M. Reder Gadow (1984); M. Reder Gadow (1985).

67. J. P. Blanco Carrasco, M. García Fernández y F. Olival (2019), 7-11.

68. La Casa de Expósitos de Málaga está necesitada aún de profundos estudios, pese a la dificultad que entraña la pérdida de parte de su documentación. Vid. M. P. JiMÉNEZ GutiérRez (2019).

69. F. García GonzÁlez (2005); M. García Fernández (2019). 
municipal y sus decisiones, aunque también citaremos fructíferas líneas como las festividades, entendidas como exaltación del poder local y regio ${ }^{70}$ o las circunstancias devenidas en contextos belicosos que supusieron, entre otras cuestiones, el levantamiento de una específica infraestructura.

La representación se convirtió en un elemento clave con la entrada a la modernidad. Tras la cristianización de la ciudad, el siguiente paso vino dado por la nueva organización urbana entre la que destacaría la apertura de vías más amplias, calle Nueva sería ejemplo de ello, o la reconversión de las viejas mezquitas en iglesias cristianas ${ }^{71}$. En suma, los dos órganos de poder, el secular y el eclesiástico, asentaban el control social sobre una base eminentemente cultural, la alfabetización iconográfica fue llave de adoctrinamiento de una población mayoritariamente analfabeta ${ }^{72}$.

Por otro lado, con la incorporación a Castilla, la ciudad de Málaga quedaba bajo las directrices de su nuevo ente administrativo: el cabildo. La conformación, estructura interna o la venalidad de los cargos de esta institución fue profusamente estudiado en el último tercio del siglo pasado ${ }^{73}$. En los 70 resaltaríamos las aportaciones de Domínguez Ortiz y Tomás y Valiente $^{74}$; ya en los 80 trabajos venidos de la mano de González Alonso y su estudio sobre la administración de la corona castellana o de Cuartas Rivero $^{75}$; y en la siguiente década un aumento en la producción gracias a contribuciones hechas por Hernández Benítez o Gelabert ${ }^{76}$.

Para el caso malagueño al estudio sobre los corregidores del XVII de Pérez de Colosía o el de Pereiro Barbero para el XVI ${ }^{77}$ se sumaron los realizados por Ybáñez Worboys para el reinado de Carlos I y Felipe II $^{78}$. Regidores, escribanos, jurados o procuradores han sido analizados por la

70. Sobre la imbricación entre la historia política y cultura vide R. J. LóPez LóPEz (2011).

71. Acerca de la política arquitectónica vide J. Suberbiola Martínez (1997); sobre el escudo de la ciudad tras la cristianización D. Sedeño Ferrer (2000).

72. Las tesis de la historia cultural han evolucionado desde consideraciones tradicionales, donde la relación entre la lectoescritura y la alfabetización era indisociable, hasta posiciones con enfoques más amplios donde se parte del conocimiento de un contexto altamente impregnado por una cultura leída y, por ende, conocida por el aparente analfabeto. R. CHARTiER (2010).

73. A. Jiménez Estrella (2012).

74. A. Domínguez Ortiz (1975); F. Tomás y Valiente (1975).

75. B. González Alonso (1981); M. Cuartas Rivero (1983).

76. M. Hernández Benítez (1995); J. E. Gelabert González (1997).

77. P. Pereiro Barbero (1987); M. I. Pérez de Colosía Rodríguez (1997).

78. Cabe mencionar además a E. Cruces Blanco, E. López de Coca Castañer, J. M. Ruiz Povedano (2017). 
historiadora como observatorio a través del cual comprender el proceso de formalización de una élite política con escaso arraigo en la ciudad ${ }^{79}$. Con todo ello, la profesora Ybáñez se posicionaba como una de las mayores conocedoras del cabildo malagueño del quinientos gracias a una investigación que también tomó como objeto analítico la representación o ejemplificación del poder, verdadero núcleo de su tesis doctoral ${ }^{80}$ : El cabildo municipal y las ceremonias públicas en Málaga durante el reinado de Carlos I.

El siglo XVII, además del referido artículo de Colosía, ha sido tratado de forma ocasional al igual que para el XVIII donde tan solo podríamos citar a Villas Tinoco en cuanto a la política reformista llevada a cabo por la monarquía borbónica, mientras que, para el caso veleño, Pezzi Cristóbal incidía en el control concejil de la economía local ${ }^{81}$. Mucho por hacer, por tanto, en el resto de los municipios.

Sobre los aspectos militares, escasamente representados porcentualmente, se han caracterizado por su tratamiento tangencial desde dos puntos de vista: por un lado, haciendo hincapié en los proyectos de infraestructura ante ofensivas contrarias y, por otro, focalizando los análisis sobre las milicias locales. La historia militar en España, y siguiendo las distintas tendencias vistas durante el desarrollo del presente trabajo, ha sufrido un gran crecimiento desde los últimos años, hecho que vienen señalando desde los diversos balances historiográficos que sobre la materia se han publicado ${ }^{82}$, aunque la atención tiende a la desigualdad si comparamos los estudios sobre el ejército profesional con los llevados a cabo para las milicias locales mimetizadas desde el XVII con las provinciales para reaparecer a finales del XVIII como milicias urbanas ${ }^{83}$. Esta "institución arcaica", como bien la definió Pezzi Cristóbal, ha sido estudiada de forma general, es decir, no focalizada en la milicia malagueña strictu sensu para el caso de la capital. Por el contrario, tan solo Vélez cuenta con un artículo sobre los cargos y la otorgación de privilegios hacia aquellos que la integraron ${ }^{84}$.

Es en la infraestructura militar donde más se ha incidido. La posición estratégica de Málaga, tanto desde el punto de vista geopolítico como co-

79. P. YbáÑEz Worboys (1999); (2002).

80. P. YbáÑ̃z Worboys (1997); (1998). También la Dra. Reder Gadow publicó cuatro artículos $(1983,1995,1996,1997)$ sobre las exequias de las reinas María Luis de Orleans, Mariana de Austrias y Luisa Isabela de Orleans y de Felipe V realizadas en Málaga.

81. P. Pezzi Cristóbal (1996); S. Villas Tinoco (1997).

82. E. Martínez Ruiz (2003); A. Jiménez Estrella (2015); C. Borreguero Beltrán (2016).

83. S. Villas Tinoco (1988), 488.

84. P. Pezzi Cristóbal (2004). 
mercial, hará indispensable el avituallamiento ante posibles incursiones, primero turcas y luego inglesas. Empero, las edificaciones castrenses no fueron suficientes y los daños que durante la conquista se produjeron a las murallas aún en el siglo XVII no habían sido solventados ${ }^{85}$. Bajo esta situación se explican los diferentes intentos de fortificación de la ciudad entre los que destacaríamos la visita de Pedro Pacheco durante el reinado de Felipe IV $^{86}$ o los proyectos defensivos de su puerto durante el siglo XVIII, debido a "la pujanza que toman las obras públicas con el nuevo gobierno [de Felipe V]" donde Málaga se verá beneficiada ${ }^{87}$.

En conjunto podemos decir que es una vía aún por explotar pese a que somos conocedores de investigaciones en curso desarrolladas desde la universidad de Málaga sobre el papel de los ingenieros militares por parte de Víctor García González ${ }^{88}$.

\subsection{El estudio de la religiosidad y el arte como elemento de difusión}

Detengámonos, aunque brevemente, en lo que algunos han denominado "la otra cara de la luna" 89 , esto es, la religiosidad popular y, de forma conjunta, en su indisociable reflejo artístico ${ }^{90}$. Según las palabras de LópezGuadalupe, el avance de las investigaciones sobre ella ha ido desdibujando cada vez más el concepto popular, donde "la confluencia, no sin roces, entre lo oficial y lo popular en la etapa del catolicismo barroco tiene que ver con ello" ${ }^{91}$, hecho sobre el que abunda García Cárcel, considerando que "el adjetivo popular ha quedado sin referencias sociológicas de clase sino meramente identificable con lo abundantemente consumido" ${ }^{92}$. Por el contrario, el de religiosidad, tomando nuevamente las palabras de LópezGuadalupe, "se mostraba tan amplio como cómodo" y añadía: "Parece caber en él de todo" ${ }^{93}$.

85. J. C. Sánchez Escutia (1988).

86. J. Gil Sanjuán (2003).

87. M. I. Pérez de Colosía Rodríguez (1983), 276; para el castillo de San Lorenzo vide C. Viñes Millet (1979).

88. V. García GonzÁlez (2016).

89. W. A. Christian (1991), citado por J. M. Usunáriz Garayoa (1999), 18.

90. J. M. Usunáriz Garayoa (1999).

91. M. L. López-Guadalupe MuÑoz (2013), 11-12.

92. R. García Cárcel (2001), 207.

93. M. L. López-Guadalupe MuÑoz (2013), 12. 
Dicha temática ha tenido un desarrollo extraordinario en nuestro país, gracias primero a la influencia de la historiografía francesa $y$, en segundo lugar, al sobresaliente avance de la historia cultural. Si a finales de los 70 las perspectivas no auguraban un gran futuro, hubo que esperar hasta la década posterior donde se celebraron citas científicas como el coloquio Culturas populares en la Casa de Velázquez (1983) o, en Sevilla, el I Encuentro sobre Religiosidad Popular (1987) ${ }^{94}$. Fueron los 90 una época de consolidación donde se mantuvieron periódicas reuniones e, incluso, una joven Asociación Española de Historia Moderna, nacida en 1988, dedicaba una sección a las mentalidades e ideologías, donde era tratado, entre otras cuestiones, el ejercicio devocional ${ }^{95}$.

Como mencionamos al comienzo, los estudios desde la Historia del Arte no son profusos en Baetica, disminuyendo paralelamente a la consolidación de otra revista especializada propia de la universidad de Málaga. No obstante, durante los 80-90 investigadores como Camacho Martínez o Sánchez López publicaban interesantes artículos sobre la cuestión. Destacamos en este sentido un trabajo del profesor Sánchez que, sin olvidar la extrema interrelación entre el arte y la mentalidad, se introducía en el estudio del asociacionismo Barroco a través de las distintas piezas devocionales, en este caso marianas ${ }^{96}$, advocación sobre la que han incidido otras investigaciones más recientes ${ }^{97}$.

Pero fue en adversas coyunturas cuando la religiosidad actuó con mayor énfasis. Las sucesivas epidemias, los conflictos bélicos o las catástrofes naturales que azotaron a la sociedad son, por consiguiente, un escenario sobresaliente de análisis histórico. En el primero de los casos, aun contando con trabajos anteriores como el de Fernández Basurte sobre la piadosa respuesta ante los brotes de peste que azotaron a Málaga capital en la primera mitad del XVII ${ }^{98}$, hemos de destacar la investigación de la historiadora León Vegas sobre las respuestas asistenciales dadas en la Antequera moderna $^{99}$, incluyendo también la producción artística. Es por ello por lo que su investigación no solo logró desentrañar las formas de pensamiento

94. J. M. UsunÁriz Garayoa (1999).

95. L. C. Álvarez Santaló y C. M. Cremades Griñán (1993).

96. J. A. Sánchez López (1993).

97. E. García Gil (2018).

98. F. Fernández Basurte (1994).

99. Su tesis titulada El sistema benéfico-asistencial en la Antequera moderna. Plan hospitalario y calamidades públicas (siglos XVII-XVIII) fue defendida en la universidad de Málaga en 2005. Vide M. León Vegas (2007a). 
y actuación, sino que también enmarcó en su contexto histórico las piezas devocionales de una urbe que, fruto de su esplendor, se caracterizó por la riqueza ornamental ${ }^{100}$.

\section{ALGUNAS LÍNEAS FUTURAS DE INVESTIGACIÓN}

Tras este breve repaso por los artículos contenidos en la actual revista Baetica. Estudios de Historia Moderna y Contemporánea, y aunque algunas han sido apuntadas a lo largo de las páginas que preceden, es óptimo, más que elaborar unas conclusiones, plantear algunas líneas futuras de investigación para el avance en el conocimiento de la provincia de Málaga en los siglos modernos en relación con las tendencias actuales en la producción española.

En el terreno de la historia social, y con la intención de mantener el esquema seguido durante el artículo, el análisis de las minorías, no solo morisca o judeoconversa sino también otras como los esclavos, han evolucionado hacia posiciones cualitativas con estudios sobre la vida cotidiana, integración y movilidad social o, incluso, ciclos vitales pese a que ello requiera un dificultoso tratamiento de documentación notarial, escasamente utilizada para el siglo $\mathrm{XVI}^{101}$.

La historia social a partir del análisis familiar también es hoy un campo de escaso tratamiento en Málaga. Su proliferación desde los 80 ha llevado a una inclusión de variedad temática como el curso de vida del hogar, jefatura femenina, estrategias y trayectorias tanto familiares como individuales e, influenciadas por la antropología, las características estereotipadas trasmitidas a través de las artes y la tratadística. También en este campo podríamos citar la historia de la vida cotidiana y la cultura material que, como vimos, cuenta hoy con un desarrollo pleno en la geografía universitaria española, con la que podremos conocer también el sentimiento devocional haciendo hincapié en el mobiliario doméstico, por poner solo un ejemplo.

Otra de las cuestiones, entre lo social y lo económico, podría venir referido en el interés por la historia rural que favorecería además a paliar su escasa presencia en el panorama actual, en el que los estudios de García González o Rey Castelao serían buen punto de partida ${ }^{102}$. En este sentido nombramos

100. M. LeÓn Vegas (2007b).

101. A. J. Morgado García (2016); E. Soria Mesa (2018).

102. F. García González (2015); O. Rey Castelao (2015); F. García González y F. BoadJAABA (2017). 
también al retorno gremial. Su proliferación en España desde finales de los años 90 ha abierto una panoplia de oportunidades, desde la conflictividad intra y extra-gremial a los estudios sobre el aprendizaje o la oficialía, todo ello desde una perspectiva interdisciplinar donde la antropología histórica ha influido enormemente. Cabría citar al respecto al grupo taller de Historia Social donde se integran Nieto Sánchez, Zofío Llorente o López Barahona ${ }^{103}$.

Con respecto a la historia política y cultural, se podrían realizar algunas investigaciones sobre las clases dirigentes de la ciudad, su relación con el ámbito comercial, donde la obra de Villar García será de inestimable ayuda, la representación de su estatus o su ámbito de actuación ${ }^{104}$. Así como indagar en los cabildos de importantes enclaves como los de Antequera y Ronda observando los posibles ascensos generacionales por el cursus honorum administrativo.

Seguras son las ausencias, aunque tenemos el convencimiento que de una forma u otra el análisis historiográfico y temático visto en los sucesivos números de Baetica es ampliable al conjunto de la investigación histórica de la universidad de Málaga, primero por su extensa existencia y segundo, por la calidad y novedad científica. Pese a ello, la perseguida excelencia sigue derroteros distintos y lo que se pretendía con este recorrido histográfico, vislumbrar la importancia de la revista para la historia de Málaga, ha de ser pasado, debiendo ser difundida por otros cauces, alejándonos del microcosmos local para adentrarnos a un cruce académico en el marco de lo global.

\section{BIBLIOGRAFÍA}

Álvarez Santaló, León Carlos y Cremades Griñán, Carmen María (eds.) (1993), Mentalidad e ideología en el Antiguo Régimen. II Reunión Científica Asociación Española de Historia Moderna, vol. II, Universidad, Murcia.

Arias de SaAvedra Alíss, Inmaculada (2012), "La historia de la vida cotidiana hoy", en ARias de SaAvedra Alías, Inmaculada (coord.), Vida cotidiana en la España de la ilustración, Universidad, Granada, pp. 7-32.

Aróstegur Sánchez, Julio (1995), La investigación histórica: teoría y método, Crítica, Madrid.

Bernal Rodríguez, Antonio Miguel (2003), "Riesgo y ventura de la Historia local. Andalucía", en Martínez SÁnchez, Juan J. (coord.), II Congreso de Historia local. Metodología de la investigación, Gobierno de Canarias, La Orotava, pp. 219-235.

103. J. C. Zofío Llorente (2005); J. A. Nieto SÁnchez (2006); V. López Barahona (2016). 104. V. Mínguez Cornelles (2013). 
Birriel Salcedo, Margarita (ed.) (2017), La(s) casa(s) en la Edad Moderna, Instituto Fernando el Católico, Zaragoza.

Blanco Carrasco, José Pablo; García Fernández, Máximo y Olival, Fernanda (2019), "Presentación”, en J. P. Blanco Carrasco, M. García Fernández y F. Olival (coords.), Jóvenes y juventud en los espacios ibéricos durante el Antiguo Régimen. Vidas en construcción, Colibrí, Lisboa, pp. 7-11.

Borreguero Beltrán, Cristina (2016), "La historia militar en el contexto de las nuevas corrientes historiográficas. Una aproximación”, Manuscrits, 34, pp. 145-176.

Bravo CARo, Juan Jesús (1988), “Aproximación al fenómeno repoblador en Algarrobo durante el último tercio del siglo XVI", Baetica. Estudios de Arte, Geografia e Historia, 11, pp. 377-383.

- (1995), Felipe II y la repoblación del reino de Granada: la Taha de Comares, Universidad, Granada.

— (2003), "Extranjeros “de paso" en la Antequera de 1631", Baetica. Estudios de Arte, Geografia e Historia, 25, pp. 505-525.

- (2004), "Antequera, destino de la emigración temporal francesa (1631-1638)", Baetica. Estudios de Arte, Geografia e Historia, 26, pp. 283-305.

Cañas Pelayo, Marcos Rafael (2015), "Los judeoconversos portugueses de la Edad Moderna en la historiografía española", Revista de Historiografía, 23, pp. 217-243.

Chacón JimÉnez, Francisco (2014), El viaje de las familias en la sociedad española. Veinte años de historiografia, Editum, Murcia.

Chartier, Roger (2010), “Aprender a leer, leer para aprender", Nuevo mundo, mundos nuevos, 10, pp. 23-39.

Clavero Salvador, Bartolomé (1991), "Historia social altomoderna: entre la generalidad y la especialidad", en S. Castillo Alonso (coord.), La Historia Social en España. Actualidad y perspectivas, Siglo XXI, Madrid, pp. 219-228.

Cruces Blanco, Esther, lópez de Coca Castañer, Enrique y Ruiz Povedano, José María (2017), Málaga y el almirantazgo mayor del reino de Granada (1510-1538). Revolución y poder, Fundación Unicaja, Madrid.

Cuartas Rivero, Margarita (1983), "La venta de oficios públicos en el siglo XVI", Actas del IV Symposium de Historia de la Administración, Instituto Nacional de Administración Pública, Madrid, pp. 225-260.

Domínguez Ortiz, Antonio (1970), "La venta de cargos y oficios públicos en Castilla y sus consecuencias económicas y sociales", Anuario de Historia Económica y Social, III, pp. 105-137.

Dubert, Isidro (2015), “La demografía de la Época Moderna en España. Una perspectiva comparada, 1980-2012”, en O. Rey Castelao y F. SuÁRez Golán (eds.), Los vestidos de Clío. Métodos y tendencias recientes de la historiografía modernista española (1973-2013), Universidad, Santiago de Compostela, pp. 113-149. 
Fernández Basurte, Federico (1994), “Epidemias y manifestaciones religiosas en la Málaga del siglo XVII. La virgen de la Victoria", Baetica. Estudios de Arte, Geografía e Historia, 16, pp. 305-319.

Fernández Paradas, Mercedes (2000), "Los bienes rústicos de propios antequeranos (siglos XV-XVIII)", Baetica. Estudios de Arte, Geografía e Historia, 22, pp. 483-500.

- (2001), "Fuentes para el estudio de las tierras municipales: el patrimonio territorial del Concejo de Antequera", Baetica. Estudios de Arte, Geografía e Historia, 23, pp. 659-673.

Franco Rubio, Gloria Ángeles (2012), "La historia de la vida cotidiana en la historiografía modernista española: algunas reflexiones", en G. A. Franco Rubio (coord.), La vida de cada día: rituales, costumbres y rutinas cotidianas en la España Moderna, Asociación Cultural Almudayna, Madrid, pp. 17-66.

GARCíA CÁRCEL, Ricardo (1977), "La historiografía sobre los moriscos españoles. Aproximación a un estado de la cuestión”, Estudis. Revista de Historia Moderna, 6, pp. 71-100.

- (1996), "Veinte años de historiografía sobre la Inquisición", en La inquisición y la sociedad española, Real Sociedad Económica de Amigos del País, Valencia, pp. 231-254.

- (2001), "La reciente historiografía modernista española", Chronica Nova, 28, pp. 185-219.

García Fernández, Máximo (coord.) (2013), Cultural material y vida cotidiana moderna. Escenarios, Sílex, Madrid.

- (2019), Los caminos de la juventud en la Castilla Moderna. Menores, huérfanos y tutores, Sílex, Madrid.

GARCía GiL, Elizabeth (2018), “Advocación mariana y ceremonial religioso en la documentación del archivo de la Catedral de Málaga: una aproximación a las fiestas, misas y dotaciones", Baetica. Estudios de Historia Moderna y Contemporánea, 38, pp. 115-133.

García González, Francisco (coord.) (2005), Vejez, envejecimiento y sociedad en España, siglos XVI-XXI, Universidad de Castilla-La Mancha, Cuenca.

- (2007), "La historia de la familia en el mundo rural. La contribución del Seminario Familia y Élite de Poder y la Asociación de Demografía Histórica”, en F. Chacón Jiménez y J. Hernández Franco (eds.), Espacios sociales, universos familiares. La familia en la historiografía española, Editum, Murcia, pp. 107-135.

- (coord.) (2009), La historia moderna en España y el hispanismo francés, Marcial Pons y Facultad de Humanidades, Madrid y Albacete.

- (2015), "Investigar historia rural en España y Francia en la Época Moderna. Impulso y renovación desde la historia comparada", en O. REY CASTELAO y F. SuÁrez Golán (eds.), Los vestidos de Clío. Métodos y tendencias recientes de la historiografía modernista española (1973-2013), Universidad, Santiago de Compostela, pp.171-203. 
García González, Francisco y BoudjaAba, Fabrice (2017), "Introducción al dossier: El trabajo doméstico y sirviente en la Europa rural (ss. XVI-XIX). Diversidad de modelos regionales y formas de dependencia", Mundo Agrario. Revista de Estudios Rurales, vol. 18, 39, pp. 1-6.

García GonzÁlez, Víctor (2016), “La creación del Real Cuerpo de Ingenieros a través de su fundador D. Jorge Próspero de Verboom, y el ejemplo de un proyecto ilustrado. La reforma del puerto de Málaga (1717-1723)", en A. M. Prieto García y M. J. Rodríguez Trejo (eds.), Métodos y perspectivas de investigación en Historia Moderna, Universidad, Cáceres, pp. 144-156.

García Hernán, David; Soriano Triguero, Carmen; Negredo del Cerro, Fernando y Sanz de Bremond y Mayans, Ana (1994), "El legado del 92 y la historiografía sobre la Edad Moderna. Pautas para su análisis”, Cuadernos de Historia Moderna, 15, pp. 417-446.

Gelabert González, Juan Eloy (1997), "Tráfico de oficios y gobierno de los pueblos en Castilla (1543-1643)”, en L. Rosa y L. A. Riвot García (dirs.), Ciudad y mundo urbano en la época moderna, Actas, Madrid, pp. 157-186.

Gil SanjuÁn, Joaquín (1978), "La Inquisición de Granada: visita a Málaga y su comarca en 1568", Baetica. Estudios de Arte, Geografía e Historia, 1, pp. 313-336.

- (2003), "Visita a Málaga de don Pedro Pacheco, comisario militar de Felipe IV", Baetica. Estudios de Arte, Geografia e Historia, 25, pp. 527-545.

González Alonso, Benjamín (1981), Sobre el Estado y la administración de la Corona de Castilla en el Antiguo Régimen. Las Comunidades de Castilla $y$ otros estudios, Siglos XXI, Madrid.

Hernández Benítez, Mauro (1995), A la sombra de la Corona: poder y oligarquía urbana (Madrid, 1606-1808), Siglos XXI, Madrid.

Hernández García, Ricardo y GonzÁlez Arce, José Damián (2015), “Gremios y corporaciones laborales. Debates historiográficos y estado de la cuestión”, Áreas. Revista Internacional de Ciencias Sociales, 34, pp. 7-18.

Hernández SANDOICA, Elena (2004), Tendencias historiográficas actuales. Escribir historia hoy, Akal, Madrid.

Hidalgo Fernández, Francisco (2018), "De hidalgos a caballeros, de artesanos a oligarcas. La trayectoria social de los Gálvez (1700-1870)", Baetica. Estudios de Historia Moderna y Contemporánea, 38, pp. 159-191.

JACQUES, Jean (1972), Las luchas sociales en los gremios, Miguel Castellote, Madrid.

Jiménez Gutiérrez, María del Pilar (2019), "Los “hijos del pecado": una aproximación a la Casa de Expósitos de Málaga en la segunda mitad de la centuria ilustrada", Baetica. Estudios de Historia Moderna y Contemporánea, 39, pp. 219-250.

Jiménez Estrella, Antonio (2012), "Poder, dinero y ventas de oficios y honores en la España del Antiguo Régimen: un estado de la cuestión", Cuadernos de Historia Moderna, 37, pp. 259-272. 
- (2015), "La historiografía militar sobre la España moderna en los últimos años", en Labrador Arroyo, Félix (ed.), II Encuentro de Jóvenes Investigadores en Historia Moderna. Lineas recientes de investigación en Historia Moderna, Universidad Rey Juan Carlos, Madrid, pp. 13-48.

Lacomba Abellán, Juan Antonio (1995), "Sobre historia local y microhistoria. Una aproximación”, Isla de Arriarán, 6, pp. 129-136.

- (2012), "La historia local y su importancia", en V. Leis SÁnchez; L. Martínez Aguilar y L. Rabaneda Sánchez (coords.), Actas I Congreso de Historia de Linares, Centro de Estudios de Linares, Jaén, pp. 455-470.

León Vegas, Milagros (2002), "La Hermandad de los Pobres de la Cárcel de Antequera (siglos XVI-XVII)", Baetica. Estudios de Arte, Geografía e Historia, 24, pp. 355-375.

- (2004), "Abstinencia sexual en tiempo de cuaresma: la prostitución a comienzos del siglo XVII", Baetica, Estudios de Arte, Geografia e Historia, 26, pp. 321-337.

- (2007a), Dos siglos de calamidades públicas en Antequera: crisis epidémicas y calamidades públicas (siglos XVII-XVIII), Fundación Municipal de Cultura, Antequera.

- (2007b), “ ¿Fe o superstición? Devociones populares ante lo "sobrenatural” en la Antequera moderna", Baetica. Estudios de Arte, Geografia e Historia, 29, pp. 321-345.

- (2011), "Negro sobre blanco: la Antequera moderna en sus fuentes bibliográficas", Baetica. Estudios de Arte, Geografia e Historia, 33, pp. 299-315.

López BARAHona, Victoria (2016), Las trabajadoras en la sociedad madrileña del siglo XVIII, Asociación Científica y Cultural Iberoamericana, Madrid.

López Beltrán, María Teresa (1979), "El Puerto de Málaga en la transición a los tiempos modernos. Introducción a su estudio", Baetica. Estudios de Arte, Geografia e Historia, 2 (I), pp. 187-203.

- (1997), "Financiación de los viajes y cobertura de los riesgos del tráfico marítimo malagueño en época de los Reyes Católicos. I: cambios y préstamos marítimos", Baetica. Estudios de Arte, Geografia e Historia, 19 (II), pp. 51-63.

- (1999), "Financiación de los viajes y cobertura de los riesgos del tráfico marítimo malagueño en época de los Reyes Católicos. II: seguros marítimos", Baetica. Estudios de Arte, Geografía e Historia, 21, pp. 281-300.

- (2008), "La sexualidad delictiva en Málaga y su obispado en los libros de Penas de Cámara (siglos XV-XVI)", Baetica. Estudios de Arte, Geografía e Historia, 30, pp. 223-248.

LóPez-GuadaluPe MuÑoz, Miguel Luis (2013), "Religiosidad triunfante, religiosidad domesticada. Entre la justificación y la reflexión", Chronica Nova, 39, pp. 11-17.

LÓPEZ LÓPEZ, Roberto Javier (coord.) (2011), "Dossier: Poder, imagen, opinión pública y propaganda en la Edad Moderna", Obradoiro de Historia Moderna, 20, 407 págs. 
Marín Gelabert, Miquel (2001), "Historiadores locales e historiadores universitarios. La historiografía española en su contexto internacional, 1948-1965", en C. Forcadell Álvarez y I. Peiró Martín (coords.), Lecturas de la historia: nueve reflexiones sobre la historia de la historiografía, Institución Fernando el Católico, Zaragoza, pp. 97-150.

Martínez Ruiz, Enrique (2003), "La eclosión de la historia militar", Studia Historica. Historia Moderna, 25, pp. 17-25.

Mínguez Cornelles, Víctor (coord.) (2013), Las artes y la arquitectura del poder, Universitat Jaume I, Castellón de la Plana.

Molas Ribalta, Pere (1970), Los gremios barceloneses del siglo XVIII, Confederación Española de Cajas de Ahorro, Madrid.

- (2006), "La obra de María Isabel Pérez de Colosía”, Baetica. Estudios de Arte, Geografía e Historia, 28 (II), pp. 7-10.

Morgado García, Arturo Jesús (2016), "El ciclo vital de los esclavos en el Cádiz de la Modernidad", Revista de Historia Moderna, 34, pp. 297-315.

Nieto Sánchez, José Antolín (2006), Artesanos y mercaderes: una historia social y económica de Madrid, 1450-1850, Fundamentos, Madrid.

Ocaña Cuadros, Ivanova (2002), "Las regidurías del cabildo malagueño en los primeros años del reinado de Felipe V (1700-1715)", en J. L. Pereira Iglesias (coord.), Felipe $V$ de Borbón 1701-1746. Actas del Congreso de San Fernando (Cádiz) de 27 de noviembre a 1 de diciembre de 2000, Universidad de Córdoba y Ayuntamiento de San Fernando, Córdoba y San Fernando, pp. 209-234.

- (2009), "Una familia oriunda de Amberes en el cabildo municipal malagueño: los Swerts", en J. J. Bravo Caro y J. Sanz Sampelayo (coords.), Población y grupos sociales en el Antiguo Régimen. IX Reunión Cientifica de la Fundación Española de Historia Moderna, vol. 2, Área de Historia Moderna de la Universidad, Málaga, pp. 1039-1062.

Pereiro Barbero, Presentación (1987), "Los oficiales municipales de "justicia” y "orden público" a mediados del siglo XVI: teoría y práctica de su función", Baetica. Estudios de Arte, Geografía e Historia, 10, pp. 281-292.

Pérez de Colosía Rodríguez, María Isabel (1983), "Proyecto de Bartolomé Thurus para el puerto de Málaga (siglo XVIII)", Baetica. Estudios de Arte, Geografía e Historia, 6, pp. 275-282.

- (1985), "La viña de Alonso Gamarra: centro del criptojudaísmo malagueño en el siglo XVII", Baetica. Estudios de Arte, Geografía e Historia, 8, pp. 377-391.

- (1997), "Corregidores malagueños durante la segunda mitad del siglo XVII", Baetica. Estudios de Arte, Geografia e Historia, 19 (II), pp. 135-147.

- (2003), "Constituciones para la Casa de Recogidas fundada por fray Alonso de Santo Tomás", Baetica. Estudios de Arte, Geografia e Historia, 25, pp. 575-588.

PÉrez García, José Manuel (1990), “La historiografía en Demografía Histórica española durante la Edad Moderna: un estado de la cuestión”, Manuscrits, 8, pp. 41-70. 
Pérez SAmper, María Ángeles (2009), "La historia de la historia de la alimentación”, Chronica Nova, 35, pp. 105-162.

Pezzi Cristóbal, Pilar (1994), “Aspectos económicos del Cabildo de Vélez-Málaga a principios del siglo XVIII", Baetica. Estudios de Arte, Geografía e Historia, 16, pp. 345-356.

- (1995), "El precio de la máquina burocrática: salarios y gastos administrativos en el cabildo de Vélez-Málaga", Baetica. Estudios de Arte, Geografía e Historia, 17, pp. 421-436.

- (1996), "Vélez-Málaga y el control capitular de la vida económica", Baetica. Estudios de Arte, Geografía e Historia, 18, pp. 409-419.

- (2003a), Pasa y limón para los países del norte: economía y fiscalidad en Vélez-Málaga en el siglo XVIII, Universidad, Málaga.

- (2003b), El gobierno municipal de Vélez-Málaga en el siglo XVIII, Diputación, Málaga.

- (2003c), "Las dificultades de una fundación religiosa: Alonso de Carrión y la enseñanza de la juventud veleña", Baetica. Estudios de Arte, Geografía e Historia, 25, pp. 589-606.

- (2004), "La milicia local en la jurisdicción de Vélez-Málaga. Provisión de cargos y reparto de privilegios", Baetica. Estudios de Arte, Geografía e Historia, 26, pp. 353-368.

- (2006), "Los fundamentos de la nobleza en Vélez-Málaga: los paradigmas de un modelo nobiliario sin nobleza", Baetica. Estudios de Arte, Geografía e Historia, 28 (II), pp. 457-475.

REDER Gadow, Marion (1984), “Aproximación a una institución docente femenina: el colegio de niñas huérfanas Nuestra Señora de la Concepción de María Santísima", Baetica. Estudios de Arte, Geografía e Historia, 7, pp.

— (1985), "Una institución docente del siglo XVIII: los niños de la providencia", Baetica. Estudios de Arte, Geografía e Historia, 8, pp.

Rey Castelao, Ofelia (2009), "El contexto internacional del modernismo español, 1983-2007”, en M. EsteBAn DE Vega (ed.), 25 años de Historia. La revista Studia Historica en la historiografía española, Universidad, Salamanca, pp. 99-124.

- (2015), "El trabajo de las mujeres rurales en la España Moderna: un balance historiográfico", Revista de Historiografía, 22, pp. 183-210.

RoldÁn PAZ, Lorena (2004), "Control de conciencias en la periferia: visitas inquisitoriales a la ciudad de Antequera en el siglo XVII", Baetica. Estudios de Arte, Geografía e Historia, 26, pp. 369-388.

- (2010), "Los cómplices en la viña de Alonso Gamarra. Aproximación a un grupo criptojudaizante", Baetica. Estudios de Arte, Geografía e Historia, 32, pp. 449-469.

- (2015), El problema judeoconverso durante el siglo XVII: el caso malagueño, Tesis Doctoral, tutorizada por Juan Jesús Bravo Caro, Universidad, Málaga. 
SÁEnz Lorite, Manuel (1997), "Semblanza del profesor García Manrique”, Baetica. Estudios de Arte, Geografía e Historia, 19 (I), pp. 9-13.

SÁnchez Escutia, Juan Carlos (1988), "Consideraciones sobre la defensa y los arrebatos en la ciudad de Málaga bajo el reinado de Felipe III", Baetica. Estudios de Arte, Geografía e Historia, 11, pp. 453-464.

SÁnchez López, Juan Antonio (1993), "Arte y mentalidad en una asociación popular del Barroco: el Rosario de los Remedios", Baetica. Estudios de Arte, Geografia e Historia, 15, pp. 31-52.

SÁnchez Prieto, Juan María (2001), "La historia imposible del mayo francés", Revista de Estudios Políticos, 112, pp. 109-133.

Santana Guzmán, Antonio Jesús (2012), "Dotaciones y proyectos urbanos para una nueva capital", en M. Méndez BAIGEs (ed.), Arquitectura, ciudad y territorio en Málaga (1900-2011), Geometría, Málaga, pp. 227-272.

Sanz Sampelayo, Juan Félix (1980), Granada en el siglo XVIII, Diputación, Granada. - (1988), "La tipología poblaciones de Málaga y su provincia según el censo de 1787", Baetica. Estudios de Arte, Geografía e Historia, 11, pp. 465-486.

Sedeño Ferrer, Daniel (2000), "Escudo de armas de la ciudad de Málaga", Baetica. Estudios de Arte, Geografía e Historia, 22, pp. 359-371.

Soria Mesa, Enrique (2000), "Los estudios sobre las oligarquías locales municipales en la Castilla moderna. Un balance en claroscuro", Manuscrits, 18, pp. 185-197.

- (2018), "Falsificadores, usurpadores y herejes: la familia Baños de Granada, de moriscos islamizantes a marqueses", eHumanista: Journal of Iberian Studies, 40, pp. 296-315.

Soria Mesa, Enrique y Otero Mondéjar, Santiago (2010), “Una nueva encrucijada. La reciente historiografía sobre los moriscos", Tiempos Modernos, 7, 21, pp. 1-13.

Suberbiola Martínez, Jesús (1997), "Política arquitectónica de los obispos de Málaga tras la conquista (1485-1540)", Baetica. Estudios de Arte, Geografía e Historia, 19 (II), pp. 67-82.

Tomás y Valiente, Francisco (1975), "La venta de oficios de regidores y la formación de oligarquías urbanas en Castilla (siglos XVII y XVIII)", Historia. Instituciones. Documentos, 2, pp. 523-547.

UsunÁRIZ GARAYOA, Jesús María (1999), “Los estudios sobre religiosidad popular en la España moderna en los últimos veinticinco años", Zainak, 18, pp. 17-43.

Vicente Algueró, Felipe José de (1976), Conflictos e ideologías en la Universidad, Editorial Prensa Española y Editorial Magisterio Español, Madrid.

Villas Tinoco, Siro (1978), “Aproximación al estudio de los gremios malagueños en el siglo XVIII", Baetica. Estudios de Arte, Geografia e Historia, 1, pp. 391-402.

- (1979), Málaga en tiempos de la Revolución Francesa, Universidad, Málaga

- (1985), Los Gremios malagueños, 1700-1746, Universidad, Málaga.

- (1988), "Milicia y municipio malagueño en torno a 1775", Baetica. Estudios de Arte, Geografía e Historia, 11, pp. 487-496. 
- (1996), Estudio sobre el Cabildo Municipal malagueño en la Edad Moderna, Diputación Provincial, Málaga

- (1997), "Reformismo y municipios", Baetica. Estudios de Arte, Geografía e Historia, 19 (II), pp. 209-222.

Villar García, María Begoña (1982), Los extranjeros en Málaga en el siglo XVIII, Monte de Piedad y Caja de Ahorros, Córdoba.

- (1983), "El estudio de la vivienda en el siglo XVIII. Una propuesta de método", Baetica. Estudios de Arte, Geografia e Historia, 6, pp. 307-315.

- (2003), "Presentación”, en M. B. Villar García y P. Pezzi Cristóbal (eds.), Los extranjeros en la España moderna. Actas del I Coloquio Internacional. Málaga 28-30 de noviembre de 2002, vol. I, Ministerio de Educación y Ciencia, Junta de Andalucía, Patronato de la Costa del Sol, Asociación Hispano-Alemana de Málaga y la Costa del Sol, Consulado General de Alemania, Unicaja, Universidad, Ayuntamiento y Diputación Provincial de Málaga, Málaga, pp. 15-19.

ViÑes Millet, Cristina (1979), "En torno a una sala de armas en el castillo de San Lorenzo. Notas sobre el puerto de Málaga en el siglo XVIII", Baetica. Estudios de Arte, Geografia e Historia, 2 (II), 255-276.

YBÁÑEZ Worboys, Pilar (1997), "Los regocijos de toros en los albores de la Modernidad”, Baetica. Estudios de Arte, Geografía e Historia, 19 (II), pp. 223-232.

- (1998), "Fiestas representativas de la política beligerante de Carlos I", Baetica. Estudios de Arte, Geografia e Historia, 20, pp. 415-426.

- (1999), "Las regidurías malagueñas en la primera mitad del Quinientos", Baetica. Estudios de Arte, Geografía e Historia, 21, pp. 383-399.

- (2002), "Sistematización de los oficios en el ayuntamiento malacitano", Baetica. Estudios de Arte, Geografía e Historia, 24, pp. 479-490.

Zofío Llorente, Juan Carlos (2005), Gremios y artesanos en Madrid, 1550-1650: la sociedad del trabajo en una ciudad cortesana preindustrial, Instituto de Estudios Madrileños, Madrid. 